\title{
INTEGRAÇÃO DA SUSTENTABILIDADE EM FERRAMENTA PROJETUAL: FEAP-SUS
}

\section{FEAP-SUS: INTEGRATION OF SUSTAINABILITY IN DESIGN TOOL}

\author{
Paulo Cesar Machado Ferroli* E-mail: ferroli@cce.ufsc.br \\ Lisiane Ilha Librelotto** E-mail: lisiane.librelotto@unisul.br \\ *UFSC - Universidade Federal de Santa Catarina, Florianópolis, SC \\ ${ }^{* *}$ UNISUL - Universidade do Sul de Santa Catarina, Florianópolis, SC
}

\begin{abstract}
Resumo: Design de produtos é uma atividade que requer criatividade, senso de gerenciamento, grande capacidade de síntese e conhecimentos gerais e específicos sobre a área do projeto. Atualmente, em virtude do volume expressivo de dados e informações, o designer/projetista precisa utilizar-se de metodologias, ferramentas e técnicas de projeto que o auxiliem no exercício profissional da atividade, de modo que possa englobar todos os fatores relevantes, priorizando os principais, sem negligenciar nenhum. Isso exige uma atitude multidisciplinar por essência, envolvendo várias áreas do conhecimento e obrigando o designer a possuir uma boa capacidade de gerenciamento de informações (gestão do design). Incorpora-se à essa problemática a inclusão da sustentabilidade, influenciando a atividade sob os aspectos básicos que a constituem: sustentabilidade econômica, social e ambiental. Baseando-se nessa necessidade, esse trabalho apresenta o desenvolvimento da ferramenta FEAP-SUS (Ferramenta Auxiliar para Projeto com ênfase na Sustentabilidade). O estudo de caso foi realizado em trabalhos de TCC (Trabalho de Conclusão de Curso) do curso de Design Industrial da UNIVALI (Universidade do Vale do Itajaí).
\end{abstract}

Palavras-chaves: Desenvolvimento de ferramenta projetual. Sustentabilidade - design. Gestão; Meioambiente.

\begin{abstract}
Industrial Design is an activity that requires creativity, sense of management, great capacity of synthesis and much knowledge in the design area. Considering by virtue of the expressive volume of data and information, the designer uses methodologies, tools and techniques project that help this activity. These fools needs priors relevant factors, without neglecting any of them. This demands an interdisciplinary attitude towards the essence, involving several areas of knowledge and forcing the designer to a good management capacity of information (design management). Adding to this matter is also the inclusion of sustainability, and the aspects that constitute it: economic sustainability, social and environmental. So, this work presents the development of the FEAP - SUS tool. The Study Case was applied in Project Graduation from the Industrial Design Course at the UNIVALI.
\end{abstract}

Keys-words: Development of a design tool. Sustainability. Industrial design. Management. Environment.

\section{INTRODUÇÃO}

O homem é a espécie dominante do planeta, fato decorrente de ser o único ser vivo com capacidade criativa para modificar o ambiente que o cerca com 
objetivos de garantir sua sobrevivência ou satisfazer desejos. As primeiras modificações realizadas eram resultantes do instinto básico de sobrevivência, assemelhando-se ao praticado pelos demais animais, como caçar e pescar, por exemplo. Aos poucos, as intervenções no meio tornaram-se mais agressivas, incorporando atividades como derrubar árvores (utilizando sua madeira para fabricar ferramentas, armas ou utensílios); construir cabanas, praticar a agricultura, utilizarse de minérios, fibras, etc..

Enquanto as outras espécies mantinham (e mantém) uma relação de equilíbrio com a natureza (retirando desta apenas o necessário para sua sobrevivência) o homem percebeu que poderia "lucrar" com o meio-ambiente, explorando-o em benefício próprio. A espécie humana passou a valorar as coisas (incluindo espécies vivas, inclusive a sua própria, a exemplo da escravidão) e assim, adotou uma atitude predatória com relação ao meio ambiente. Tal postura evoluiu para a retirada de recursos numa taxa superior a de recuperação da área afetada. Almeida (2007) explica que os recursos ambientais, hoje tidos como uma espécie de capital, é ameaçado por duas razões básicas: a ausência de direito de propriedade (ou seja, não tem dono definitivo) e a fungibilidade, que significa que ele não pode ser substituído por outro de mesma espécie, qualidade, quantidade e valor. Logo, o fato de serem definidos como externalidades (produtos globais de uso comum) origina o uso insustentável desses recursos.

Grande parte da degradação atual pode ser atribuída ao mau uso da principal característica dos projetistas: a criatividade. No intuito de tornar nossa vida mais confortável, prazerosa, segura, entre outras nobres causas, ou seja, de termos cada vez mais "qualidade de vida", esforços globais foram empreendidos resultando em máquinas e equipamentos cada vez mais complexos e dependentes de energia. $O$ sistema sócio-econômico resultante municiou a corrida cada vez mais intensa de oferta, sempre buscando cativar (ou conquistar) uma clientela eternamente "insatisfeita", diminuindo drasticamente o ciclo de vida da maioria dos produtos.

Por muito tempo, os fatores relevantes para o sucesso de um novo produto incluíam aspectos atrativos, mercadológicos, sociais, ergonômicos, produtivos, econômicos, fabris, financeiros, tecnológicos, etc. que buscavam saciar as necessidades sempre crescentes de uma população que passou a ser (ao longo dos anos) incentivada ao consumo, ao descarte de produtos ainda em bom estado de 
uso, preteridos por constantes novos lançamentos, levando a um consumo ecologicamente insustentável.

Segundo Manzini e Vezzoli (2008), design deve ser entendido de acordo com seu significado amplo e atual, não se aplicando apenas ao produto físico (definido por material, forma e função), mas estendendo-se ao sistema - produto, ou seja, ao conjunto integrado de produto, serviço e comunicação.

Dentro dessa linha de pensamento os autores destacam que o design é a atividade que deve "ligar" o tecnicamente possível com o ecologicamente necessário atuando dentro de quatro níveis de interferência: redesign ambiental de produtos já existentes; projeto de novos produtos para substituição dos atuais; projeto de novos produtos - serviços intrinsecamente sustentáveis; e proposta de novos cenários para um novo estilo de vida sustentável. Até o momento, a atuação profissional das pessoas ligadas as áreas projetuais está, quase na totalidade dos casos, restrita aos dois primeiros níveis, que, embora útil e necessária, é insuficiente para atingir a sustentabilidade ambiental, garantida apenas pelos outros dois níveis (Design for Sustainability). Há, portanto, uma necessidade clara de alteração comportamental na atividade de projeto, passando a enfocar mudanças de paradigmas toda vez que se faz o projeto de um novo produto.

É nesse cenário de transição que o presente trabalho está focado, desenvolvendo uma ferramenta que auxilie designers a buscar a sustentabilidade em sua totalidade, ou seja, na íntegra de seu conceito, abordando as dimensões econômica, social e ambiental. Com isso, estabelecem-se as seguintes condições básicas para a equipe de projeto:

- conhecimento do ciclo de vida do projeto (Life Cycle Design). Através dele, o designer deverá conseguir conceber novos produtos com a consciência de que, durante todas as fases de projeto, serão consideradas as possíveis implicações ambientais ligadas as fases do ciclo de vida do produto (pré-produção, produção, distribuição, uso e descarte), buscando desse modo minimizar todos os efeitos negativos possíveis (MANZINI; VEZZOLI, 2008);

- definição das necessidades do público-alvo e estabelecimento consensual entre projeto, produção, marketing e distribuição, dos requisitos da qualidade necessários para atendê-las. Isso pode ser Revista Produção Online. Florianópolis, SC, v.11, n. 2, p. 447-475, abr./jun., 2011. 
obtido, por exemplo, pela técnica do QFD - Quality Function Deployment (ROZENFELD et al., 2006);

- identificação de níveis de importância das necessidades direcionadas ao público-alvo, objetivando a quantificação e qualificação destas. Isso pode ser obtido também pelo QFD, com importante auxílio do Modelo Kano (SILVA, 2004);

- possibilidade de eliminação de alternativas geradas pelo não atendimento de necessidades básicas. Pode ser obtido pelo Método Paramétrico (MENEZES, 2001); e

- escolha da melhor alternativa projetual, levando-se em consideração todos os aspectos apontados nas pesquisas, caracterizando necessidades e estabelecendo meio quantitativo de análise da sustentabilidade projetual.

Verifica-se que as quatro primeiras condições já possuem ferramentas e/ou técnicas conceituadas, amplamente utilizadas na atividade projetual, com resultados já comprovados. Portanto, o problema refere-se a quinta condição, ou seja, de que modo o designer, engenheiro ou equipe de projeto escolherá a melhor alternativa projetual no critério sustentabilidade? Sendo assim, o objetivo geral desse estudo é o desenvolvimento de uma ferramenta que permita ao designer e/ou projetista avaliar as alternativas de projeto geradas, quantificando-as de acordo com critérios econômicos, ecológicos e sociais.

\section{REVISÃO CONCEITUAL: MÉTODOS, FERRAMENTAS E TÉCNICAS USADAS EM DESIGN DE PRODUTOS - ANÁLISE DO CRITÉRIO SUSTENTABILIDADE}

Recentemente tem-se observado um grande número de publicações específicas conceituando a atividade de projeto e design. A partir do momento em que as diversas camadas participantes direta ou indiretamente da atividade projetual percebem as complexas inter-relações existentes advindas do aumento crescente de fatores relevantes, nota-se a necessidade do estabelecimento, mediante um procedimento sistemático, de caminhos que orientem (especialmente jovens designers) na busca de soluções mais próximas possível das expectativas. 
Para Baxter (1998), as atividades de desenvolvimento de um novo produto requerem pesquisa, planejamento cuidadoso, controle meticuloso e uso de métodos sistemáticos, exigindo uma abordagem interdisciplinar (atividades de marketing, engenharia de produtos e processos, aplicação de conhecimentos sobre estética e estilo, etc.). Neste processo, torna-se necessário a integração entre as ciências sócio-econômicas, tecnologia e arte aplicada, que tenha como resultado um produto equilibrado.

Em definições clássicas de projeto (BACK et. al., 2008) observa-se que a palavra "restrições" aparece com destaque, fato que mostra a complexidade de atuação em um ambiente repleto de restrições, sem que ocorra a inibição da criatividade. O gerenciamento das restrições projetuais é considerado como uma das mais graves deficiências de profissionais em início de carreira, especialmente porque as técnicas de criatividade não fornecem bons resultados se houver algum tipo de restrição inicial imposta.

É consenso entre especialistas da área a necessidade atual de os profissionais que trabalham com projeto de produtos precisarem ser, mais do nunca, interdisciplinares. Do contrário, não conseguirão contornar as inúmeras restrições impostas, sejam estas advindas do mercado, dos consumidores, de questões financeiras, técnicas, operacionais, ecológicas, e assim por diante.

Santos (2005) comenta que grande parte dos métodos de projeto surgidos ao longo dos anos 1960 a 1990 abordavam as necessidades do mercado e apresentavam uma estrutura complexa, composta de muitas inter-relações ligadas as etapas, prendendo a ação de projeto ao enfoque e objetivos específicos. Ou seja, são métodos que prevêem início, meio e fim, através de tarefas executadas de forma lógica e seqüencial. O autor complementa o raciocínio mostrando que sem uma estrutura que incentive a interferência no método pode-se estar deixando de se trabalhar questões importantes da formulação do futuro profissional de design. Competências e habilidades como senso crítico e a postura proativa devem ser estimulados, o que pode não ocorrer com a aplicação de métodos prontos. 


\subsection{Inclusão da sustentabilidade no projeto de produtos}

Desde o início do uso da expressão "desenvolvimento ecologicamente correto", a partir de 1986 (PAULI, 1996), academia, sociedade, governos e empresas tem se esforçado no aprimoramento conceitual, objetivando a correta inclusão do fator ecológico no projeto de produtos. Da evolução conceitual gerada por diversas pesquisas ao longo das quase três décadas desde o conceito original, a principal é a necessidade da promoção da sustentabilidade como um todo, alicerçada pelo inter-relacionamento dos fatores econômicos e ecológicos, considerado na tríade da sustentabilidade conhecida como ESA - Econômica, Social, Ambiental (LIBRELOTTO, 2009). Esta, ao ser incorporada aos projetos de novos produtos, objetiva a manutenção do meio-ambiente, sem prejuízo do incremento produtivo necessário ao atendimento das necessidades humanas.

De acordo com Manzini e Vezzoli (2008), o design para sustentabilidade somente será verdadeiramente reconhecido se houver uma constante avaliação das implicações ambientais que são relacionadas com as possibilidades projetadas de ordem técnica, econômica e social, além de levar em consideração todos os condicionantes que determinam o ciclo de vida do produto.

A maior parte dos métodos disponíveis na bibliografia (BACK e outros, 2008; BAXTER, 2000; ROZENFELD e outros, 2006) costuma abordar todo o processo de desenvolvimento de produtos, ou seja, basicamente projeto conceitual, projeto preliminar e projeto detalhado, inseridos dentro do ciclo de vida do produto, que envolve todas as etapas e atividades necessárias para tornar concreto um produto. Dentro desse contexto, a questão da sustentabilidade, embora citada e definida sempre como algo importante, tende a passar quase que despercebida no intrincado volume de fatores relevantes a serem considerados. A gestão do processo de design, considerando-se o exposto, envolve uma atividade mais eficaz, direcionada ao incremento da qualidade de vida das pessoas, buscando uma harmonia entre a satisfação das necessidades dos clientes usuários, com a preservação do planeta.

É importante neste sentido verificar o estudo encontrado em Santos (2005), realizado por Abramovitz e Freitas (2000), utilizando a técnica Delphi, com especialistas na área do design, que indicaram quais as áreas teriam interface de 
maior relevância com o projeto. Como resultado, apresenta-se os dados fornecidos no quadro 1.

Quadro 1 - Áreas de maior interface com o projeto.

\begin{tabular}{|l|l|l|l|}
\hline $\begin{array}{l}\text { Classificaç } \\
\text { ão }\end{array}$ & Área de interface & $\begin{array}{l}\text { Classificaçã } \\
0\end{array}$ & Áreas de interface \\
\hline $1^{0}$ lugar & Criatividade e ergonomia & $2^{0}$ lugar & $\begin{array}{l}\text { Questões tecnológicas, de } \\
\text { materiais e processos produtivos }\end{array}$ \\
\hline $3^{0}$ lugar & $\begin{array}{l}\text { Questões ecológicas e e } \\
\text { representações bidimensionais e } \\
\text { tridimensionais }\end{array}$ & $4^{0}$ lugar & Aspectos sociológicos e semicos \\
\hline $5^{0}$ lugar & Antropometria, cultura e cognição & $6^{0}$ lugar & Mercado, inovação e gestão \\
\hline $7^{0}$ lugar & $\begin{array}{l}\text { Gerenciamento de custos e artes } \\
\text { aplicadas }\end{array}$ & $8^{0}$ lugar & $\begin{array}{l}\text { Prioridades de } \\
\text { questões políticas e econômicas }\end{array}$ \\
\hline $9^{0}$ lugar & $\begin{array}{l}\text { Relacionamento com arquitetura, } \\
\text { engenharia e outras áreas }\end{array}$ & $10^{0}$ lugar & Impacto ambiental \\
\hline
\end{tabular}

Fonte: Santos (2005)

Embora citado em terceiro lugar como "questões ecológicas", observa-se que o impacto ambiental aparece em último lugar. A pesquisa realizada demostra também a importância da integração multidisciplinar, entendendo-se nesse contexto que a sustentabilidade plena somente é possível com um ambiente de projeto que não priorize demasiadamente nenhum dos aspectos apontados.

\section{FEAP-SUS: Ferramenta auxiliar para projeto com ênfase na sustentabilidade}

A ferramenta de projeto apresentada neste artigo foi desenvolvida inicialmente através de uma adaptação do proposto por Kepner e Tregoe apresentado em Menezes (2001), focalizando especificamente para o projeto de produtos sustentáveis, sob os enfoques ambiental, econômico e social.

Pela aplicação do referido método na análise de projetos reais (ou seja, projetos que foram efetivamente concluídos, gerando pelo menos um protótipo), observou-se que apenas o estabelecimento de critérios "deveres" ou "desejos" (como propõe o método original) é muito pouco significativo perante a grande diversidade de exigências nos projetos atuais e, ao abordar-se toda a extensão de fatores presentes em um projeto (como questões relacionadas a custo, ergonomia, processos fabris, tendências estéticas, formas, cores, modelos, mercado, marketing, logística, meio-ambiente, etc.) acaba por não permitir uma análise detalhada, originando produtos carentes de determinadas funções e/ou abordagens. Desse 
modo, verificou-se ser necessário o desenvolvimento de uma adaptação do método (ou complementação - como o sugerido nesse trabalho), objetivando torná-lo mais funcional e aplicável para projetos.

\subsection{Desenvolvimento da ferramenta FEAP-SUS}

Kano (Silva, 2004) estabelece um modelo no qual divide os chamados desejos dos clientes em três categorias de qualidades abrangidas (figura 1). Os níveis de desejos dos clientes são proporcionais à qualidade final do produto, estabelecendo-se as qualidades: obrigatória, de desempenho e de excitação.

Figura 1 - Modelo Kano da Qualidade

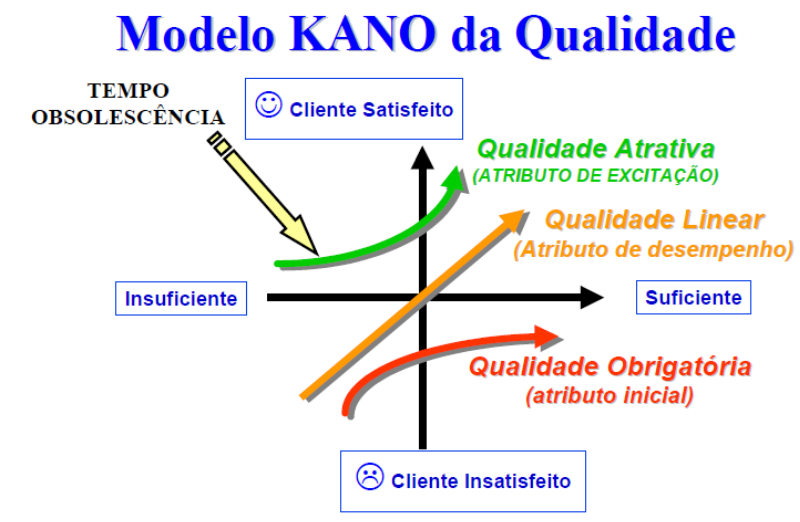

Fonte: Silva (2004)

Mediante estudos preliminares (FERROLI e LIBRELOTTO, 2007), procurouse o estabelecimento de uma abordagem de correlação entre o proposto por Kano e a ferramenta a ser desenvolvida. Desse modo, a qualidade obrigatória foi considerada como dever. Para essa, o não estabelecimento de algum de seus critérios leva a eliminação da alternativa (dever de grau 1). A qualidade de desempenho também é considerada como dever; no entanto, o não atendimento de algum de seus critérios não é, neste momento, motivo de eliminação da alternativa (dever de grau 2). Nestas condições iniciais não foi considerada a variável da sustentabilidade. A ferramenta GUT (Gravidade, Urgência e Tendência) foi usada conforme ilustra o quadro 2. 
Quadro 2 - GUT adaptado para uso da ferramenta FEAP-SUS.

\begin{tabular}{|c|c|c|c|}
\hline & G - Gravidade & U - Urgência & T-Tendência \\
\hline 5 & $\begin{array}{l}\text { Falta é considerada } \\
\text { muito grave }\end{array}$ & $\begin{array}{l}\text { Após o lançamento do } \\
\begin{array}{l}\text { produto será urgente um } \\
\text { redesign }\end{array}\end{array}$ & $\begin{array}{l}\text { Tendência do mercado é de } \\
\text { praticamente todos os modelos } \\
\text { atenderem ao quesito }(+ \text { de } 90 \%)\end{array}$ \\
\hline 3 & $\begin{array}{l}\text { A falta é considerada } \\
\text { de média gravidade }\end{array}$ & $\begin{array}{l}\text { Estima-se um redesign após } \\
\text { um prazo de } 3 \text { a } 6 \text { meses do } \\
\text { lançamento do produto }\end{array}$ & $\begin{array}{l}\text { A tendência do mercado é de que em } \\
\text { torno de } 50 \% \text { dos modelos existentes } \\
\text { atendam ao quesito }\end{array}$ \\
\hline 1 & $\begin{array}{l}\text { A falta é considerada } \\
\text { de pouca gravidade }\end{array}$ & $\begin{array}{l}\text { Não há uma estimativa à } \\
\text { médio ou curto prazo da } \\
\text { necessidade de um redesign }\end{array}$ & $\begin{array}{l}\text { Poucos modelos (até } 20 \% \text { ) disponíveis } \\
\text { no mercado atendem ao quesito }\end{array}$ \\
\hline
\end{tabular}

A pontuação dos critérios deveres de grau 2 se dá pela multiplicação dos fatores $\mathrm{G} \times \mathrm{U} \times \mathrm{T}$ (quadro 4) para cada quesito. O resultado é então multiplicado pelo grau de importância do quesito (peso), com valores variando de 1 a 10 . Esse valor, por sua vez, é multiplicado pela nota que cada alternativa obteve no quesito analisado.

Com as primeiras análises realizadas, percebeu-se que, como os valores de gravidade, urgência e tendência são inversamente proporcionais a adequação projetual (ou seja, quanto maior o valor numérico menos adequada será a alternativa), estipulou-se que esses valores deveriam ser negativos, sendo então, no final, subtraídos de valores positivos obtidos pelos itens desejos. Por tratar-se de uma escala de valores negativa (onde quanto mais alto for o resultado, tendendo a esquerda, menor será a adequação da alternativa), as notas precisam ser "corrigidas", para que seja possível a análise matemática correta. Após alguns testes, estipulou-se um fator de correção como o mostrado no quadro 3.

Exemplificando: se a alternativa " $x$ " obter uma nota 9,0 e a alternativa "y" obter uma nota 5,0 no mesmo quesito, considerando apenas a abordagem matemática direta, a alternativa " $x$ " terá uma pontuação de débito mais significativa que a alternativa "y". No entanto, são duas variáveis distintas a serem consideradas: a análise do GUT (cujo valor, quanto maior menos adequada é a alternativa) e a análise da nota da referida alternativa, que quanto maior o valor, mais adequada é a alternativa. Nestas condições, considerando apenas a parte do GUT, a alternativa que tirou nota 9,0 estaria menos adequada do que a alternativa que tirou nota 5,0, demonstrando uma incoerência. 
Quadro 3 - Correção da escala de valores do GUT para uso na ferramenta FEAP-SUS

\begin{tabular}{|l|l|l|l|}
\hline \multicolumn{1}{|c|}{ Nota } & \multicolumn{1}{c|}{ Valor a ser multiplicado } & Nota & \multicolumn{1}{c|}{ Valor a ser multiplicado } \\
\hline 10,00 & $-1,0$ & 9,00 & $-2,0$ \\
\hline 8,00 & $-3,0$ & 7,00 & $-4,0$ \\
\hline 6,00 & $-5,0$ & 5,00 & $-6,0$ \\
\hline 4,00 & $-7,0$ & 3,00 & $-8,0$ \\
\hline 2,00 & $-9,0$ & 1,00 & $-10,0$ \\
\hline
\end{tabular}

Com o uso do fator de correção, a alternativa "x" teria seu valor corrigido a um peso negativo de $-2,0$ enquanto que a alternativa " $y$ " teria seu valor corrigido a um peso de $-6,0$, ou seja, a pontuação final fica correta, considerando-se a real nota obtida pela alternativa. Com base nessas premissas, elaborou-se o quadro 4, utilizado para análise dos critérios classificados como deveres de grau 2. Para o preenchimento do quadro 4, procede-se do seguinte modo:

- Objetivo: item importante para efeito de organização, serve basicamente para identificação;

- Critérios de avaliação: nessa coluna são listados todos os critérios considerados importantes para a avaliação do referido projeto, considerados pela equipe como deveres não essenciais (deveres de grau 2) retirados preferencialmente do briefing e das considerações resultantes do conjunto de pesquisas: bibliográfica e de campo;

- GUT: nessa coluna cada critério é avaliado segundo o exposto no quadro 2, ou seja, adaptação do GUT original. As notas de cada item são colocadas na ordem gravidade - urgência - tendência, uma abaixo da outra;

Quadro 4 - Modelo para uso exclusivo da FEAP-SUS - critérios deveres de grau 2.

\begin{tabular}{|c|c|c|c|c|c|c|c|c|c|c|c|c|c|c|c|c|}
\hline \multicolumn{17}{|l|}{ Objetivo: } \\
\hline \multirow{2}{*}{$\begin{array}{c}\text { Critérios de } \\
\text { avaliação }\end{array}$} & \multirow{2}{*}{$\begin{array}{c}G \\
U \\
T \\
\end{array}$} & \multirow{2}{*}{$\begin{array}{c}\text { Resul- } \\
\text { tado } \\
\text { GUT } \\
\end{array}$} & \multirow{2}{*}{$\begin{array}{c}\text { Peso } \\
\text { critério } \\
\text { (1 a 10) }\end{array}$} & \multirow{2}{*}{$\begin{array}{c}\text { GUT } \\
x \\
\text { Peso } \\
\end{array}$} & \multicolumn{3}{|c|}{ ALTERNATIVA 1} & \multicolumn{3}{|c|}{ ALTERNATIVA 2} & \multicolumn{3}{|c|}{ ALTERNATIVA 3} & \multicolumn{3}{|c|}{ ALTERNATIVA "n" } \\
\hline & & & & & \begin{tabular}{|c|} 
Nota \\
$(1-10)$
\end{tabular} & $\begin{array}{l}\text { Fator } \\
(\mathrm{FC})\end{array}$ & $\begin{array}{l}\text { Valor } \\
\text { final }\end{array}$ & $\begin{array}{l}\text { Nota } \\
(1-10)\end{array}$ & $\begin{array}{l}\text { Fator } \\
(\mathrm{FC})\end{array}$ & $\begin{array}{l}\text { Valor } \\
\text { final }\end{array}$ & $\begin{array}{c}\text { Nota } \\
(1-10)\end{array}$ & $\begin{array}{l}\text { Fator } \\
(\mathrm{FC})\end{array}$ & $\begin{array}{l}\text { Valor } \\
\text { final }\end{array}$ & \begin{tabular}{|c|} 
Nota \\
$(1-10)$ \\
\end{tabular} & $\begin{array}{l}\text { Fator } \\
(\mathrm{FC})\end{array}$ & $\begin{array}{l}\text { Valor } \\
\text { final }\end{array}$ \\
\hline $\begin{array}{c}\text { Lista } \\
\text { dos } \\
\text { critérios } \\
\text { deveres } \\
\text { grau } 2\end{array}$ & & & & & & & & & & & & & & & & \\
\hline \multicolumn{5}{|c|}{ TOTALIZAÇÃO: } & & & & & & & & & & & & \\
\hline
\end{tabular}


- Resultado do GUT: coluna matemática onde se multiplica os valores obtidos pela análise dos itens gravidade, urgência e tendência;

- Peso do critério: estabelecido de comum acordo entre os participantes do projeto (equipe), consiste em uma análise qualitativa / quantitativa de cada critério listado, indicando-se sua ordem de importância segundo informações obtidas primeiramente no briefing e, principalmente, nas pesquisas de campo realizadas (questionários, entrevistas, observações);

- GUT x peso: coluna matemática onde se o resultado obtido na aplicação do GUT pelo peso estabelecido do referido critério;

A partir deste momento a aplicação da ferramenta através do quadro 4 passa a uma nova etapa. Até então, os valores eram gerais; válidos para todas as alternativas geradas, deste ponto em diante, os valores passam a ser individualizados para cada alternativa:

- Nota: a alternativa é analisada e, de comum acordo entre os membros da equipe, é estabelecida um valor numérico de zero a dez que corresponde, mediante uma análise qualitativa / quantitativa, a porcentagem aproximada que a alternativa que está sendo avaliada representa no cumprimento do referido critério;

- Fator de correção: preenchimento retirado do quadro 3;

- Valor final: coluna matemática que estabelece a multiplicação entre o valor numérico obtido na coluna (GUT x peso) pelo valor estipulado na coluna FC.

A última linha do quadro 4 refere-se a totalização geral de cada alternativa, utilizados posteriormente para conclusão da ferramenta juntamente com os valores obtidos no quadro 5.

Na seqüência de aplicação da ferramenta, as alternativas analisadas pelos critérios deveres de grau 2 passam então a ser analisadas pelos critérios desejos. Para isso, utiliza-se de uma planilha semelhante a anterior, porém sem a aplicação do GUT. Nesta planilha, o peso do critério é multiplicado pela nota obtida pela alternativa no quesito considerado. O resultado é multiplicado por um fator de conversão cujo valor é oscilante: entre 100 e 500. A decisão de usar esse fator deve-se a resolução de um problema matemático. Para que os valores gerados na planilha do quadro 5 possam ser diminuídos dos valores negativos obtidos na 
planilha anterior (quadro 3), gerando resultados finais positivos, emprega-se o referido valor de correção. Sabe-se que o maior valor final será o mais adequado, logo, com o uso do fator de correção evita-se o raciocínio "inverso", mais confuso, onde o menor valor negativo é o que seria o mais adequado. A planilha originalmente estabelecia valores de 100, mas caso os resultados finais ainda apresentem-se negativos, sugere-se aumentar esse fator para 200 ou mais, evitando-se o resultado final negativo. Observa-se que todos os critérios devem ser multiplicados pelo mesmo fator. O quadro 5 apresenta o modelo para análise dos critérios desejos. Para o preenchimento do quadro 5 procede-se do seguinte modo:

- Objetivo: item importante para efeito de organização;

- Critérios de avaliação: nessa coluna são listados todos os critérios considerados importantes para a avaliação do referido projeto, considerados, pela equipe, como desejos, retirados preferencialmente do briefing e das considerações resultantes do conjunto de pesquisas: bibliográfica e de campo;

- Peso do critério: estabelecido de comum acordo entre os participantes do projeto, consiste em uma análise qualitativa / quantitativa de cada critério listado, indicando-se sua ordem de importância segundo informações obtidas primeiramente no briefing e, principalmente, nas pesquisas de campo (questionários, entrevistas, observação);

Quadro 5 - Modelo para uso exclusivo da FEAP-SUS - critérios desejos.

\begin{tabular}{|c|c|c|c|c|c|c|c|c|c|c|c|c|c|}
\hline \multicolumn{14}{|l|}{ Objetivo: } \\
\hline \multirow{2}{*}{$\begin{array}{c}\text { Critérios de } \\
\text { avaliação }\end{array}$} & \multirow{2}{*}{$\begin{array}{l}\text { Peso } \\
\text { critério } \\
\text { (1 a 10) }\end{array}$} & \multicolumn{3}{|c|}{ ALTERNATIVA 1} & \multicolumn{3}{|c|}{ ALTERNATIVA 2} & \multicolumn{3}{|c|}{ ALTERNATIVA 3} & \multicolumn{3}{|c|}{ ALTERNATIVA "n" } \\
\hline & & $\begin{array}{c}\text { Nota } \\
(1-10)\end{array}$ & $\begin{array}{l}\text { Fator } \\
\text { (FC) }\end{array}$ & $\begin{array}{l}\text { Valor } \\
\text { final }\end{array}$ & $\begin{array}{l}\text { Nota } \\
(1-10)\end{array}$ & $\begin{array}{l}\text { Fator } \\
\text { (FC) }\end{array}$ & $\begin{array}{l}\text { Valor } \\
\text { final }\end{array}$ & $\begin{array}{l}\text { Nota } \\
(1-10)\end{array}$ & $\begin{array}{l}\text { Fator } \\
\text { (FC) }\end{array}$ & $\begin{array}{l}\text { Valor } \\
\text { final }\end{array}$ & $\begin{array}{l}\text { Nota } \\
(1-10)\end{array}$ & $\begin{array}{l}\text { Fator } \\
\text { (FC) }\end{array}$ & $\begin{array}{l}\text { Valor } \\
\text { final }\end{array}$ \\
\hline $\begin{array}{c}\text { Lista } \\
\text { dos } \\
\text { critérios } \\
\text { desejos }\end{array}$ & & & & & & & & & & & & & \\
\hline TALIZAÇÃO & & & & & & & & & & & & & \\
\hline
\end{tabular}

Assim como na planilha anterior, a partir desse momento o preenchimento do quadro passa a uma nova etapa. Até esse momento, os valores são gerais, ou seja, 
válidos para todos os critérios. Deste ponto em diante, os valores passam a ser individualizados para cada alternativa gerada. Procede-se o preenchimento das colunas restantes do seguinte modo:

- Nota: a alternativa é analisada e, de comum acordo entre os membros da equipe projetual, é estabelecida um valor numérico de zero a dez que corresponde, mediante uma análise qualitativa / quantitativa, a porcentagem aproximada que a alternativa que está sendo avaliada representa no cumprimento do referido critério;

- Fator de correção: de 100 a 500, depende dos valores obtidos na planilha 4 ;

- Valor final: multiplicação entre as colunas peso do critério pela nota da alternativa multiplicado finalmente pelo fator de correção.

A aplicação final da ferramenta consiste em subtrair-se dos valores obtidos do quadro 5, os obtidos no quadro 4. A alternativa que obtiver o maior valor numérico, será, teoricamente, a mais adequada.

O item seguinte deste artigo apresenta a primeira etapa de validação da ferramenta, realizado de forma comparativa (ou seja, utilizando-se do mesmo projeto) entre um estudo de aplicação da ferramenta ainda sem a variável sustentabilidade (pesquisa já publicada em Ferroli e Librelotto, 2007) e aplicação da ferramenta com a variável sustentabilidade (análise inédita).

\section{FEAP-SUS: VALIDAÇÃO INICIAL}

Após a confecção das planilhas constituintes da ferramenta FEAP-SUS tornou-se necessário a validação desta mediante testes práticos. Para efeito de prévalidação, fez-se uma aplicação da FEAP-SUS de forma comparativa, utilizando-se para isso do mesmo projeto (com e sem a inclusão da variável sustentabilidade). $O$ estudo foi realizado mediante o redesign de uma máquina utilizada em fábricas de subprodutos de origem animal: o digestor de vísceras (estudo já mostrado anteriormente em Ferroli e Librelotto, 2007 e, por isso, no presente artigo, será transcrito apenas os quadros finais obtidos). 
Quadro 6 - Necessidades dos clientes e classificação prévia em deveres e desejos.

\begin{tabular}{|c|c|c|c|}
\hline Necessidade & Dever de grau 1 & Dever de grau 2 & Desejo \\
\hline \multicolumn{4}{|l|}{ Baixo nível de ruído } \\
\hline \multicolumn{4}{|l|}{ Evitar o cozimento de vísceras } \\
\hline \multicolumn{4}{|l|}{ Evitar cheiro desagradável } \\
\hline \multicolumn{4}{|l|}{ Não ter vazamentos } \\
\hline \multicolumn{4}{|l|}{ Segurança na operação } \\
\hline \multicolumn{4}{|l|}{ Segurança elétrica } \\
\hline \multicolumn{4}{|l|}{ Segurança no descarregamento } \\
\hline \multicolumn{4}{|l|}{ Facilidade de limpeza } \\
\hline \multicolumn{4}{|l|}{ Facilidade de manutenção } \\
\hline \multicolumn{4}{|l|}{ Potência adequada } \\
\hline \multicolumn{4}{|l|}{ Consumo de vapor reduzido } \\
\hline \multicolumn{4}{|l|}{ Consumo de eletricidade reduzido } \\
\hline \multicolumn{4}{|l|}{ Aparência: cor } \\
\hline \multicolumn{4}{|l|}{ Aparência: forma e estilo } \\
\hline \multicolumn{4}{|l|}{ Durabilidade } \\
\hline \multicolumn{4}{|l|}{ Integridade física da matéria-prima } \\
\hline \multicolumn{4}{|l|}{ Regulagem automática } \\
\hline \multicolumn{4}{|l|}{ Auxílio para retirada da farinha } \\
\hline \multicolumn{4}{|c|}{ Dispositivos de informações ao operador } \\
\hline \multicolumn{4}{|c|}{ Dispositivo para evitar sujeira exterior } \\
\hline \multicolumn{4}{|l|}{ Evitar excesso de carga } \\
\hline \multicolumn{4}{|l|}{ Rapidez de processamento } \\
\hline \multicolumn{4}{|l|}{ Pouca ou nenhuma vibração } \\
\hline \multicolumn{4}{|l|}{ Evitar a queima de farinha } \\
\hline \multicolumn{4}{|c|}{ Evitar o acúmulo de gordura externa } \\
\hline \multicolumn{4}{|l|}{ Higienização entre as cargas } \\
\hline \multicolumn{4}{|l|}{ Uso de material auto-lubrificante } \\
\hline Materiais resistentes a corrosão & & & \\
\hline
\end{tabular}

De posse da classificação das necessidades, o passo seguinte foi a análise dos deveres de grau 1 das alternativas previamente projetadas. No presente estudo de caso foram geradas seis alternativas. $O$ quadro 7 apresenta o resultado da análise dos quesitos deveres de grau 1. 
Quadro 7 - Análise dos quesitos deveres de grau 1.

\begin{tabular}{|c|c|c|c|c|c|c|}
\hline \multicolumn{7}{|c|}{ Objetivo: Redesign de Digestor de vísceras de aves } \\
\hline $\begin{array}{l}\text { Critérios de } \\
\text { avaliação }\end{array}$ & $\begin{array}{c}\text { Alternativa } \\
1\end{array}$ & $\begin{array}{c}\text { Alternativa } \\
2\end{array}$ & $\begin{array}{c}\text { Alternativa } \\
3\end{array}$ & $\begin{array}{c}\text { Alternativa } \\
4\end{array}$ & $\begin{array}{c}\text { Alternativa } \\
5\end{array}$ & $\begin{array}{c}\text { Alternativa } \\
6\end{array}$ \\
\hline $\begin{array}{l}\text { Baixo nível de } \\
\text { ruído }\end{array}$ & ATENDIDO & $\begin{array}{c}\text { NÃO } \\
\text { ATENDIDO }\end{array}$ & ATENDIDO & ATENDIDO & ATENDIDO & ATENDIDO \\
\hline $\begin{array}{l}\text { Evitar o } \\
\text { cozimento de } \\
\text { vísceras }\end{array}$ & ATENDIDO & ATENDIDO & ATENDIDO & ATENDIDO & ATENDIDO & ATENDIDO \\
\hline $\begin{array}{l}\text { Evitar cheiro } \\
\text { desagradável }\end{array}$ & ATENDIDO & ATENDIDO & ATENDIDO & ATENDIDO & $\begin{array}{c}\text { NÃO } \\
\text { ATENDIDO }\end{array}$ & ATENDIDO \\
\hline $\begin{array}{l}\text { Não ter } \\
\text { vazamentos }\end{array}$ & ATENDIDO & ATENDIDO & ATENDIDO & ATENDIDO & ATENDIDO & ATENDIDO \\
\hline $\begin{array}{l}\text { Segurança na } \\
\text { operação }\end{array}$ & ATENDIDO & ATENDIDO & ATENDIDO & ATENDIDO & $\begin{array}{c}\text { NÃO } \\
\text { ATENDIDO }\end{array}$ & ATENDIDO \\
\hline $\begin{array}{l}\text { Segurança } \\
\text { elétrica }\end{array}$ & ATENDIDO & ATENDIDO & ATENDIDO & ATENDIDO & ATENDIDO & ATENDIDO \\
\hline $\begin{array}{l}\text { Segurança no } \\
\text { descarregament } \\
\text { o }\end{array}$ & ATENDIDO & $\begin{array}{c}\text { NÃO } \\
\text { ATENDIDO }\end{array}$ & ATENDIDO & ATENDIDO & ATENDIDO & ATENDIDO \\
\hline $\begin{array}{l}\text { Facilidade de } \\
\text { limpeza }\end{array}$ & ATENDIDO & ATENDIDO & ATENDIDO & ATENDIDO & ATENDIDO & ATENDIDO \\
\hline $\begin{array}{l}\text { Facilidade de } \\
\text { manutenção }\end{array}$ & ATENDIDO & ATENDIDO & ATENDIDO & ATENDIDO & $\begin{array}{c}\text { NÃO } \\
\text { ATENDIDO }\end{array}$ & ATENDIDO \\
\hline $\begin{array}{l}\text { Potência } \\
\text { adequada }\end{array}$ & ATENDIDO & ATENDIDO & ATENDIDO & ATENDIDO & ATENDIDO & ATENDIDO \\
\hline
\end{tabular}

Conforme visto no quadro 7 , duas alternativas (2 e 5) foram eliminadas por não atenderem a dois e três quesitos de grau 1 (respectivamente), considerados como de qualidade obrigatória. Seqüencialmente, as quatro alternativas restantes foram então avaliadas segundo os quesitos de qualidade de desempenho (deveres de grau 2), conforme mostra o quadro 8.

Conforme visto no quadro 8 , a alternativa 3 teve melhor desempenho dentro dos critérios considerados deveres de grau 2 (menor valor negativo), seguida das alternativas 1,4 e 2 respectivamente. Na seqüência, as alternativas foram analisadas segundo os critérios considerados desejos, conforme demostra o quadro 9. 
Quadro 8 - Análise dos quesitos deveres de grau 2.

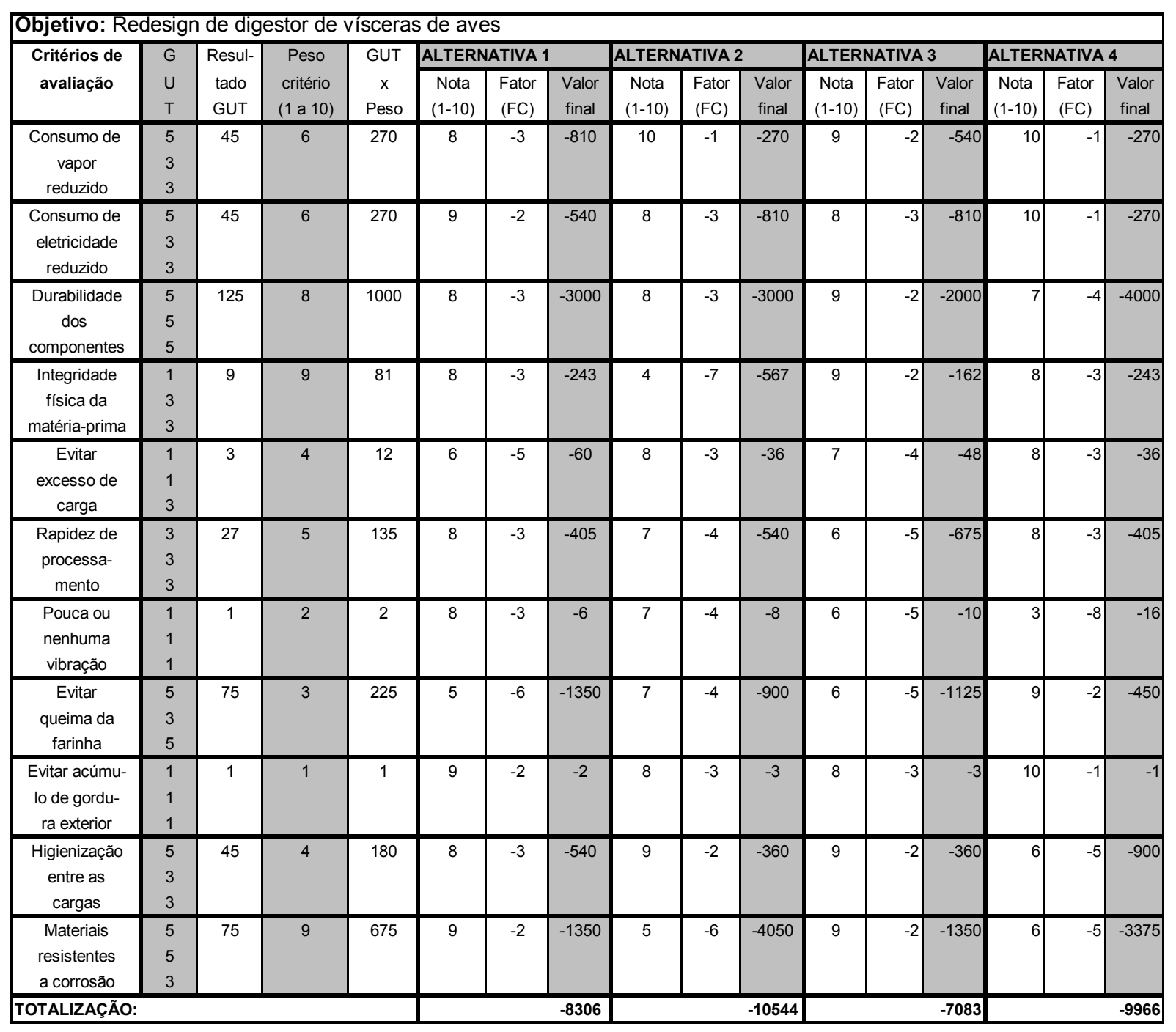

Considerando as planilhas demonstradas nos quadros mostrados, o resultado final foi:

- $\quad$ alternativa 1: $23700-8306=15394$

- alternativa 2: $35700-10544=25156$

- $\quad$ alternativa 3: $33400-7083=26317$

- alternativa 4: $30500-9966=20534$

Portanto, a alternativa 3 é, pelos critérios adotados, a mais indicada. 
Quadro 9 - Análise dos quesitos desejos.

\begin{tabular}{|c|c|c|c|c|c|c|c|c|c|c|c|c|c|}
\hline \multicolumn{14}{|c|}{ Objetivo: Redesign de digestor de vísceras de aves } \\
\hline \multirow{2}{*}{$\begin{array}{l}\text { Critérios de } \\
\text { avaliação }\end{array}$} & \multirow{2}{*}{$\begin{array}{c}\text { Peso } \\
\text { critério } \\
\text { (1 a 10) }\end{array}$} & \multicolumn{3}{|c|}{ ALTERNATIVA 1} & \multicolumn{3}{|c|}{ ALTERNATIVA 2} & \multicolumn{3}{|c|}{ ALTERNATIVA 3} & \multicolumn{3}{|c|}{ ALTERNATIVA 4} \\
\hline & & $\begin{array}{c}\text { Nota } \\
(1-10)\end{array}$ & $\begin{array}{l}\text { Fator } \\
(\mathrm{FC})\end{array}$ & $\begin{array}{l}\text { Valor } \\
\text { final }\end{array}$ & $\begin{array}{c}\text { Nota } \\
(1-10)\end{array}$ & $\begin{array}{l}\text { Fator } \\
(\mathrm{FC})\end{array}$ & $\begin{array}{l}\text { Valor } \\
\text { final }\end{array}$ & $\begin{array}{c}\text { Nota } \\
(1-10)\end{array}$ & $\begin{array}{l}\text { Fator } \\
(\mathrm{FC})\end{array}$ & $\begin{array}{l}\text { Valor } \\
\text { final }\end{array}$ & $\begin{array}{c}\text { Nota } \\
(1-10)\end{array}$ & $\begin{array}{l}\text { Fator } \\
(\mathrm{FC})\end{array}$ & $\begin{array}{l}\text { Valor } \\
\text { final }\end{array}$ \\
\hline Cor adequada & 7 & 8 & 100 & 5600 & 7 & 100 & 4900 & $\overline{7}$ & 100 & 4900 & 9 & 100 & 6300 \\
\hline $\begin{array}{l}\text { Forma e } \\
\text { estilo }\end{array}$ & 6 & 6 & 100 & 3600 & 8 & 100 & 4800 & 7 & 100 & 4200 & 5 & 100 & 3000 \\
\hline $\begin{array}{l}\text { Regulagem } \\
\text { automática }\end{array}$ & 10 & 6 & 100 & 6000 & 8 & 100 & 8000 & 9 & 100 & 9000 & 6 & 100 & 6000 \\
\hline $\begin{array}{l}\text { Auxílio para } \\
\text { retirada farinha }\end{array}$ & 9 & 2 & 100 & 1800 & 5 & 100 & 4500 & 4 & 100 & 3600 & 8 & 100 & 7200 \\
\hline $\begin{array}{l}\text { Informação } \\
\text { ao operador }\end{array}$ & 9 & 1 & 100 & 900 & 5 & 100 & 4500 & 6 & 100 & 5400 & 2 & 100 & 1800 \\
\hline $\begin{array}{c}\text { Evitar sujeira } \\
\text { exterior }\end{array}$ & 7 & 4 & 100 & 2800 & 6 & 100 & 4200 & 3 & 100 & 2100 & 2 & 100 & 1400 \\
\hline $\begin{array}{c}\text { Material } \\
\text { auto lubrificante }\end{array}$ & 6 & 5 & 100 & 3000 & 8 & 100 & 4800 & 7 & 100 & 4200 & 8 & 100 & 4800 \\
\hline TOTALIZAÇÃO: & & & & 23700 & & & 35700 & & & 33400 & & & 3050 \\
\hline
\end{tabular}

Finalizando a primeira etapa, o passo seguinte foi procurar estabelecer, junto ao público alvo da cadeia produtiva informações relevantes de caráter sustentável. Como o objetivo neste momento era apenas uma comparação, não foi incluído nenhum outro quesito, apenas analisado a categoria de sustentabilidade que cada item melhor poderia se relacionar. Para isso, elaborou-se o quadro 10.

Quadro 10 - Procedimento para inclusão da sustentabilidade na ferramenta FEAPSUS.

\begin{tabular}{|c|c|c|c|c|}
\hline \multirow{2}{*}{$\begin{array}{c}\text { Quesito } \\
\text { considerado }\end{array}$} & \multicolumn{3}{|c|}{ Sustentabilidade } & \multirow{2}{*}{ Soma } \\
\hline & Econômica & Social & Ambiental & \\
\hline & & & & \\
\hline & & & & \\
\hline & & & & \\
\hline
\end{tabular}

De acordo com o projeto, a sustentabilidade terá peso forte ( 7 - 10), médio (3 - 6) ou fraco $(0-2)$. Os critérios são somados e após multiplicados pelo que já era considerado no método antigo. O quadro 11 mostra os critérios de avaliação dos itens deveres de grau 2 e desejos tabelados segundo o quadro 10. 
Quadro 11 - Critérios de avaliação dos itens deveres de grau 2 e desejos.

\begin{tabular}{|l|c|c|c|c|}
\hline \multirow{2}{*}{ Quesito considerado } & \multicolumn{2}{c|}{ Sustentabilidade } & Soma \\
\cline { 2 - 5 } & Econômica & Social & Ambiental & \\
\hline Consumo de vapor reduzido & 9 & 7 & 10 & $\mathbf{2 6}$ \\
\hline Consumo de eletricidade reduzido & 9 & 8 & 10 & $\mathbf{2 7}$ \\
\hline Durabilidade dos componentes & 8 & 8 & 9 & $\mathbf{2 5}$ \\
\hline Integridade física da matéria-prima & 4 & 7 & 6 & $\mathbf{1 7}$ \\
\hline Evitar excesso de carga & 8 & 8 & 7 & $\mathbf{2 3}$ \\
\hline Rapidez de processamento & 7 & 8 & 6 & $\mathbf{2 1}$ \\
\hline Pouca ou nenhuma vibração & 2 & 5 & 1 & $\mathbf{8}$ \\
\hline Evitar queima de farinha & 9 & 8 & 8 & $\mathbf{2 5}$ \\
\hline Evitar acúmulo de gordura exterior & 2 & 6 & 3 & $\mathbf{1 1}$ \\
\hline Higienização entre as cargas & 5 & 9 & 7 & $\mathbf{2 1}$ \\
\hline Materiais resistentes a corrosão & 8 & 7 & 9 & $\mathbf{2 4}$ \\
\hline Cor adequada & 1 & 2 & 1 & $\mathbf{4}$ \\
\hline Forma e estilo & 9 & 8 & 9 & $\mathbf{2 6}$ \\
\hline Regulagem automática & 7 & 8 & 3 & $\mathbf{1 8}$ \\
\hline Auxílio para retirada de farinha & 7 & 9 & 7 & $\mathbf{2 3}$ \\
\hline Dispositivo de informação & 3 & 10 & 2 & $\mathbf{1 5}$ \\
\hline Evitar sujeira exterior & 10 & 10 & 10 & $\mathbf{3 0}$ \\
\hline Material auto-lubrificante & 9 & 9 & 9 & $\mathbf{2 7}$ \\
\hline
\end{tabular}

O quadro 12 mostra a categoria sustentabilidade inserida na análise dos itens deveres de grau 2 e o quadro 13 mostra a categoria sustentabilidade inserida na análise dos quesitos desejos. Nota-se que para os quesitos considerados como dever de grau 1 , não há nenhuma alteração. A análise passa a considerar os quesitos classificados como dever de grau 2 e desejos. 
Quadro 12 - Análise dos quesitos deveres de grau 2 com a variável sustentabilidade inserida.

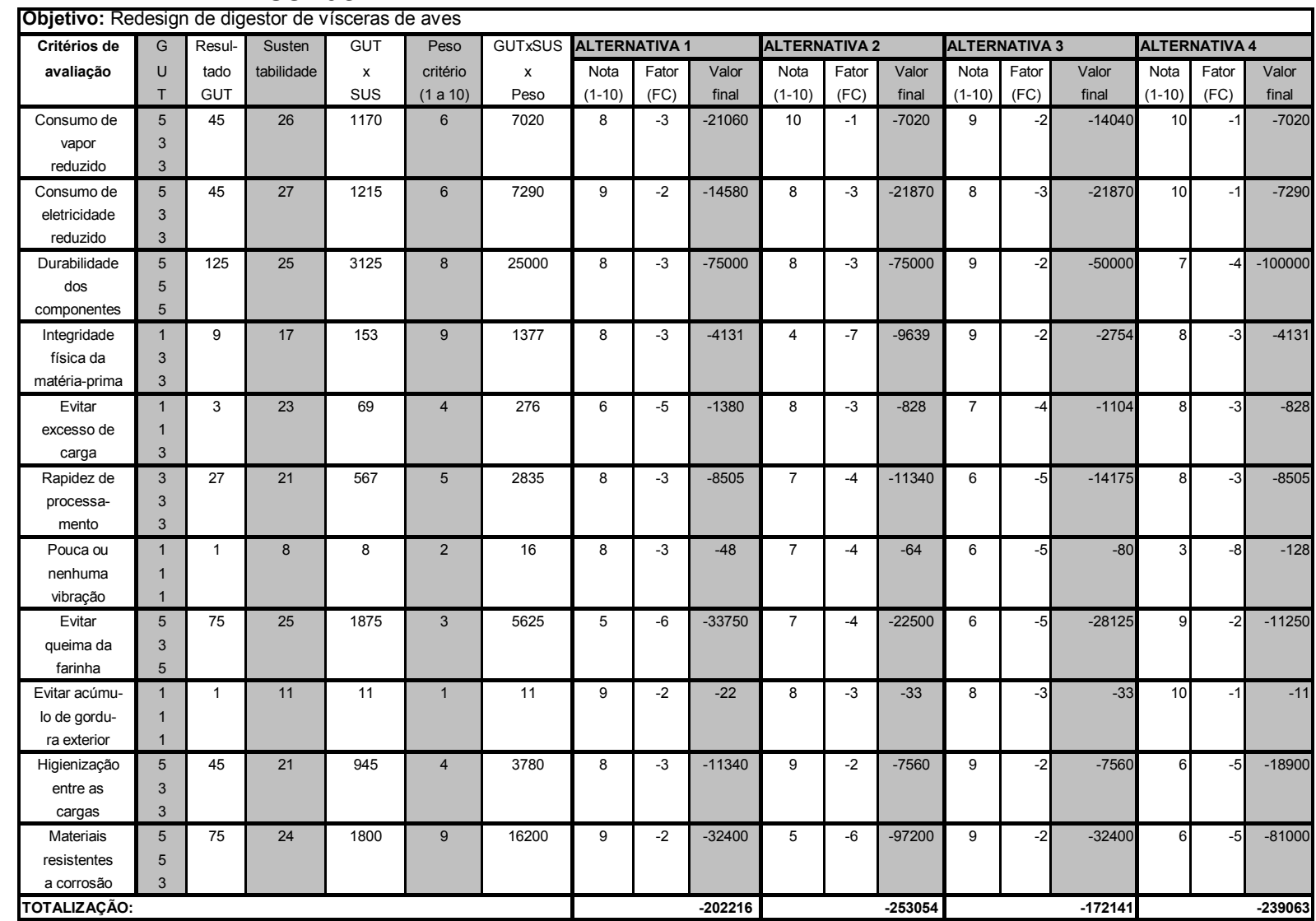

Quadro 13 - Análise dos quesitos desejos com a variável sustentabilidade inserida.

Objetivo: Redesign de digestor de vísceras de aves

\begin{tabular}{|c|c|c|c|c|c|c|c|c|c|c|c|c|c|c|c|}
\hline \multirow{2}{*}{$\begin{array}{c}\text { Critérios de } \\
\text { avaliação }\end{array}$} & \multirow{2}{*}{$\begin{array}{c}\text { Peso } \\
\text { critério } \\
\text { (1 a 10) }\end{array}$} & \multirow{2}{*}{$\begin{array}{l}\text { Susten } \\
\text { tabilidade }\end{array}$} & \multirow{2}{*}{$\begin{array}{l}\text { Peso } \\
x \\
\text { Sust. }\end{array}$} & \multicolumn{3}{|c|}{ ALTERNATIVA 1} & \multicolumn{3}{|c|}{ ALTERNATIVA 2} & \multicolumn{3}{|c|}{ ALTERNATIVA 3} & \multicolumn{3}{|c|}{ ALTERNATIVA 4} \\
\hline & & & & $\begin{array}{c}\text { Nota } \\
(1-10)\end{array}$ & $\begin{array}{l}\text { Fator } \\
\text { (FC) }\end{array}$ & $\begin{array}{l}\text { Valor } \\
\text { final }\end{array}$ & $\begin{array}{c}\text { Nota } \\
(1-10)\end{array}$ & $\begin{array}{l}\text { Fator } \\
\text { (FC) }\end{array}$ & $\begin{array}{l}\text { Valor } \\
\text { final }\end{array}$ & $\begin{array}{c}\text { Nota } \\
(1-10)\end{array}$ & $\begin{array}{l}\text { Fator } \\
\text { (FC) }\end{array}$ & $\begin{array}{l}\text { Valor } \\
\text { final }\end{array}$ & $\begin{array}{c}\text { Nota } \\
(1-10)\end{array}$ & $\begin{array}{l}\text { Fator } \\
(\mathrm{FC})\end{array}$ & $\begin{array}{l}\text { Valor } \\
\text { final }\end{array}$ \\
\hline Cor adequada & 7 & 4 & 28 & 8 & 100 & 22400 & 7 & 100 & 19600 & 7 & 100 & 19600 & 9 & 100 & 25200 \\
\hline $\begin{array}{l}\text { Forma e } \\
\text { estilo }\end{array}$ & 6 & 26 & 156 & 6 & 100 & 93600 & 8 & 100 & 124800 & 7 & 100 & 109200 & 5 & 100 & 78000 \\
\hline $\begin{array}{l}\text { Regulagem } \\
\text { automática }\end{array}$ & 10 & 18 & 180 & 6 & 100 & 108000 & 8 & 100 & 144000 & 9 & 100 & 162000 & 6 & 100 & 108000 \\
\hline $\begin{array}{l}\text { Auxilio para } \\
\text { retirada farinha }\end{array}$ & 9 & 23 & 207 & 2 & 100 & 41400 & 5 & 100 & 103500 & 4 & 100 & 82800 & 8 & 100 & 165600 \\
\hline $\begin{array}{l}\text { Informação } \\
\text { ao operador }\end{array}$ & 9 & 15 & 135 & 1 & 100 & 13500 & 5 & 100 & 67500 & 6 & 100 & 81000 & 2 & 100 & 27000 \\
\hline $\begin{array}{l}\text { Evitar sujeira } \\
\text { exterior }\end{array}$ & 7 & 30 & 210 & 4 & 100 & 84000 & 6 & 100 & 126000 & 3 & 100 & 63000 & 2 & 100 & 42000 \\
\hline $\begin{array}{c}\text { Material } \\
\text { auto lubrificante }\end{array}$ & 6 & 27 & 162 & 5 & 100 & 81000 & 8 & 100 & 129600 & 7 & 100 & 113400 & 8 & 100 & 129600 \\
\hline TOTALIZAÇÃO: & & & & & & 443900 & & & 715000 & & & 631000 & & & 575400 \\
\hline
\end{tabular}

Considerando as novas planilhas demonstradas nos quadros 12 e 13 , o resultado final foi:

- alternativa 1: $443900-202216=241684$

- alternativa 2: $715000-253054=461946$

- $\quad$ alternativa 3: $631000-172141=458859$

- alternativa 4: $575400-239063=336337$

Revista Produção Online. Florianópolis, SC, v.11, n. 2, p. 447-475, abr./jun., 2011. 
Portanto, a alternativa 2 passa a ser a mais indicada.

Conforme pode-se observar, a inclusão da sustentabilidade alterou o resultado final obtido, promovendo a validação prévia da ferramenta. Com o objetivo da validação completa, o próximo passo foi a aplicação de um estudo de caso em um trabalho de conclusão de curso (TCC) do curso de Design Industrial da UNIVALI.

\section{FEAP-SUS: validação final}

Para a validação da ferramenta utilizou-se de um trabalho de conclusão de curso (TCC) do curso de Design Industrial da UNIVALI. Para obter as informações relevantes e não constantes no relatório, entrevistou-se o autor do projeto, seu professor orientador, bem como os membros da banca avaliadora, com a finalidade dos preenchimentos das tabelas. O projeto analisado foi o intitulado G-180 Mesa de Sinuca, do acadêmico Geldson Danilo Rigailo, defendido no segundo semestre de 2007. As análises constantes nos quadros 14, 15, 16, 17 e 18 foram realizadas por um grupo formado por quatro designers industriais, um engenheiro mecânico e três estudantes de design industrial. Os dados foram obtidos basicamente pela técnica de entrevista.

Além das informações constantes no briefing, complementou-se o conjunto de necessidades com essas entrevistas e com análise detalhada das demais informações encontradas no relatório. Desse modo, o quadro 14 apresenta o conjunto de necessidades apontadas e sua classificação de acordo com a ferramenta FEAP-SUS. 
Quadro 14 - Necessidades dos clientes e classificação prévia em deveres e desejos.

\begin{tabular}{|l|l|l|l|}
\hline Necessidade & Dever de grau 1 & Dever de grau 2 & Desejo \\
\hline Quantidade de acessórios disponíveis & & & \\
\hline Poder ser usada como mesa normal & & & \\
\hline Usabilidade & & & \\
\hline Praticidade: montagem & & & \\
\hline Simplicidade: componentes e materiais & & & \\
\hline Facilidade de uso: medidas físicas & & & \\
\hline Ergonomia: altura adequada & & & \\
\hline Material resistente & & & \\
\hline Facilidade de limpeza & & & \\
\hline Atraente & & & \\
\hline Inovador & & & \\
\hline Facilidade de manutenção & & & \\
\hline Dispositivo para manter a mesa plana & & & \\
\hline Segurança ao usuário & & & \\
\hline Usar poucos materiais diferentes & & & \\
\hline Usar materiais ecologicamente corretos & & & \\
\hline Ambiente familiar: segurança para crianças & & & \\
\hline Evitar riscos no chão & & & \\
\hline Centro de gravidade: peso excessivo no lado & & & \\
\hline Disponibilidade de vários modelos & & & \\
\hline Disponibilidade de várias cores & & & \\
\hline Facilidade de transporte e manuseio interno & & & \\
\hline Leveza & & & \\
\hline Versatilidade & & & \\
\hline Quantidade de componentes reduzida & & & \\
\hline
\end{tabular}

Neste artigo não serão mostradas as alternativas geradas, apenas a análise realizada nestas. Estas podem ser encontradas em Rigailo (2007). Após finalizada a etapa de classificação das necessidades, o passo seguinte foi a análise dos deveres de grau 1 das alternativas previamente projetadas. O quadro 15 apresenta 0 resultado da análise dos quesitos deveres de grau 1. 
Quadro 15 - Análise dos quesitos deveres de grau 1.

\begin{tabular}{|c|c|c|c|c|c|c|}
\hline \multicolumn{7}{|c|}{ Objetivo: Projeto mesa de sinuca } \\
\hline $\begin{array}{l}\text { Critérios de } \\
\text { avaliação }\end{array}$ & $\begin{array}{c}\text { Alternativa } \\
1\end{array}$ & $\begin{array}{c}\text { Alternativa } \\
2\end{array}$ & $\begin{array}{c}\text { Alternativa } \\
3\end{array}$ & $\begin{array}{c}\text { Alternativa } \\
4\end{array}$ & $\begin{array}{c}\text { Alternativa } \\
5\end{array}$ & $\begin{array}{c}\text { Alternativa } \\
6\end{array}$ \\
\hline $\begin{array}{l}\text { Ergonomia - } \\
\text { altura adequada }\end{array}$ & ATENDIDO & ATENDIDO & ATENDIDO & ATENDIDO & ATENDIDO & ATENDIDO \\
\hline $\begin{array}{l}\text { Segurança ao } \\
\text { usuário }\end{array}$ & ATENDIDO & $\begin{array}{c}\text { NÃO } \\
\text { ATENDIDO }\end{array}$ & ATENDIDO & ATENDIDO & ATENDIDO & ATENDIDO \\
\hline $\begin{array}{l}\text { Segurança para } \\
\text { crianças }\end{array}$ & ATENDIDO & $\begin{array}{c}\text { NÃO } \\
\text { ATENDIDO }\end{array}$ & ATENL & ATENDIDO & ATENDIDO & $\begin{array}{c}\text { NÃO } \\
\text { ATENDIDO }\end{array}$ \\
\hline $\begin{array}{l}\text { Centro de } \\
\text { gravidade }\end{array}$ & $\overline{\mathrm{DO}}$ & ATENDIDO & ATEI & ATEI & ATE & ATENDIDO \\
\hline $\begin{array}{l}\text { Critérios de } \\
\text { avaliação }\end{array}$ & $\begin{array}{c}\text { Alternativa } \\
7\end{array}$ & $\begin{array}{c}\text { Alternativa } \\
8\end{array}$ & $\begin{array}{c}\text { Alternativa } \\
9\end{array}$ & $\begin{array}{c}\text { Alternativa } \\
10\end{array}$ & $\begin{array}{c}\text { Alternativa } \\
11\end{array}$ & $\begin{array}{c}\text { Alternativa } \\
12\end{array}$ \\
\hline $\begin{array}{l}\text { Ergonomia - } \\
\text { altura adequada }\end{array}$ & $\begin{array}{c}\text { NÃO } \\
\text { ATENDIDO } \\
\end{array}$ & ATENDIDO & ATENDIDO & $\begin{array}{c}\text { NÃO } \\
\text { ATENDIDO }\end{array}$ & ATENDIDO & ATENDIDO \\
\hline $\begin{array}{l}\text { Segurança ao } \\
\text { usuário }\end{array}$ & ATENDIDO & ATENDIDO & ATENDIDO & ATENDIDO & ATENDIDO & ATENDIDO \\
\hline $\begin{array}{l}\text { Segurança para } \\
\text { crianças }\end{array}$ & ATENDIDO & ATENDIDO & $\begin{array}{c}\text { NÃO } \\
\text { ATENDIDO } \\
\end{array}$ & $\begin{array}{c}\text { NÃO } \\
\text { ATENDIDO } \\
\end{array}$ & ATENDIDO & ATENDIDO \\
\hline $\begin{array}{l}\text { Centro de } \\
\text { gravidade }\end{array}$ & $\begin{array}{c}\text { NÃO } \\
\text { ATENDIDO }\end{array}$ & ATENDIDO & $\begin{array}{c}\text { NÃO } \\
\text { ATENDIDO }\end{array}$ & $\begin{array}{c}\text { NÃO } \\
\text { ATENDIDO }\end{array}$ & ATENDIDO & ATENDIDO \\
\hline
\end{tabular}

Pela análise dos critérios de qualidade obrigatórios, cinco alternativas foram eliminadas por não atenderem a pelo menos um dos requisitos. Na seqüência de aplicação da ferramenta, as sete alternativas restantes foram então analisadas segundo os quesitos de qualidade de desempenho (deveres de grau 2), conforme mostra o quadro 17. O quadro 16 apresenta a análise preliminar para preenchimento do quadro 17, abordando os quesitos de sustentabilidade nas dimensões econômica, social e ambiental. 
Quadro 16 - Análise dos quesitos de sustentabilidade.

\begin{tabular}{|c|c|c|c|c|}
\hline \multirow[t]{2}{*}{ Quesito considerado } & \multicolumn{3}{|c|}{ Sustentabilidade } & \multirow[t]{2}{*}{ Soma } \\
\hline & Econômica & Social & Ambiental & \\
\hline Quantidade de acessórios disponíveis & 7 & 6 & 9 & 22 \\
\hline Poder ser usada como mesa normal & 5 & 9 & 7 & 21 \\
\hline Usabilidade & 6 & 7 & 5 & 18 \\
\hline Praticidade: montagem & 9 & 7 & 5 & 21 \\
\hline Simplicidade: componentes e materiais & 10 & 8 & 9 & 27 \\
\hline Facilidade de uso: medidas físicas & 8 & 7 & 4 & 19 \\
\hline Ergonomia: altura adequada & 8 & 7 & 8 & 23 \\
\hline Material resistente & 9 & 4 & 6 & 19 \\
\hline Facilidade de limpeza & 7 & 9 & 9 & 25 \\
\hline Atraente & 4 & 4 & 3 & 15 \\
\hline Inovador & 4 & 3 & 6 & 13 \\
\hline Facilidade de manutenção & 9 & 5 & 10 & 24 \\
\hline Dispositivo para manter a mesa plana & 4 & 5 & 5 & 14 \\
\hline Segurança ao usuário & 6 & 8 & 8 & 22 \\
\hline Usar poucos materiais diferentes & 9 & 5 & 10 & 24 \\
\hline Usar materiais ecologicamente corretos & 10 & 10 & 10 & 30 \\
\hline Ambiente familiar: segurança para crianças & 6 & 9 & 8 & 22 \\
\hline Evitar riscos no chão & 6 & 4 & 8 & 18 \\
\hline $\begin{array}{l}\text { Centro de gravidade: peso excessivo no } \\
\text { lado }\end{array}$ & 5 & 5 & 7 & 17 \\
\hline Disponibilidade de vários modelos & 8 & 8 & 6 & 22 \\
\hline Disponibilidade de várias cores & 8 & 8 & 6 & 22 \\
\hline Facilidade de transporte e manuseio interno & 7 & 6 & 8 & 21 \\
\hline Leveza & 3 & 7 & 6 & 16 \\
\hline Versatilidade & 5 & 5 & 6 & 16 \\
\hline Quantidade de componentes reduzida & 9 & 6 & 9 & 24 \\
\hline
\end{tabular}

Prosseguindo a análise, o quadro 17 demonstra a análise dos quesitos relacionados como deveres de grau 2 e no quadro 18 os quesitos desejos (qualidade atrativa). 
Quadro 17 - Análise dos itens deveres de grau 2.

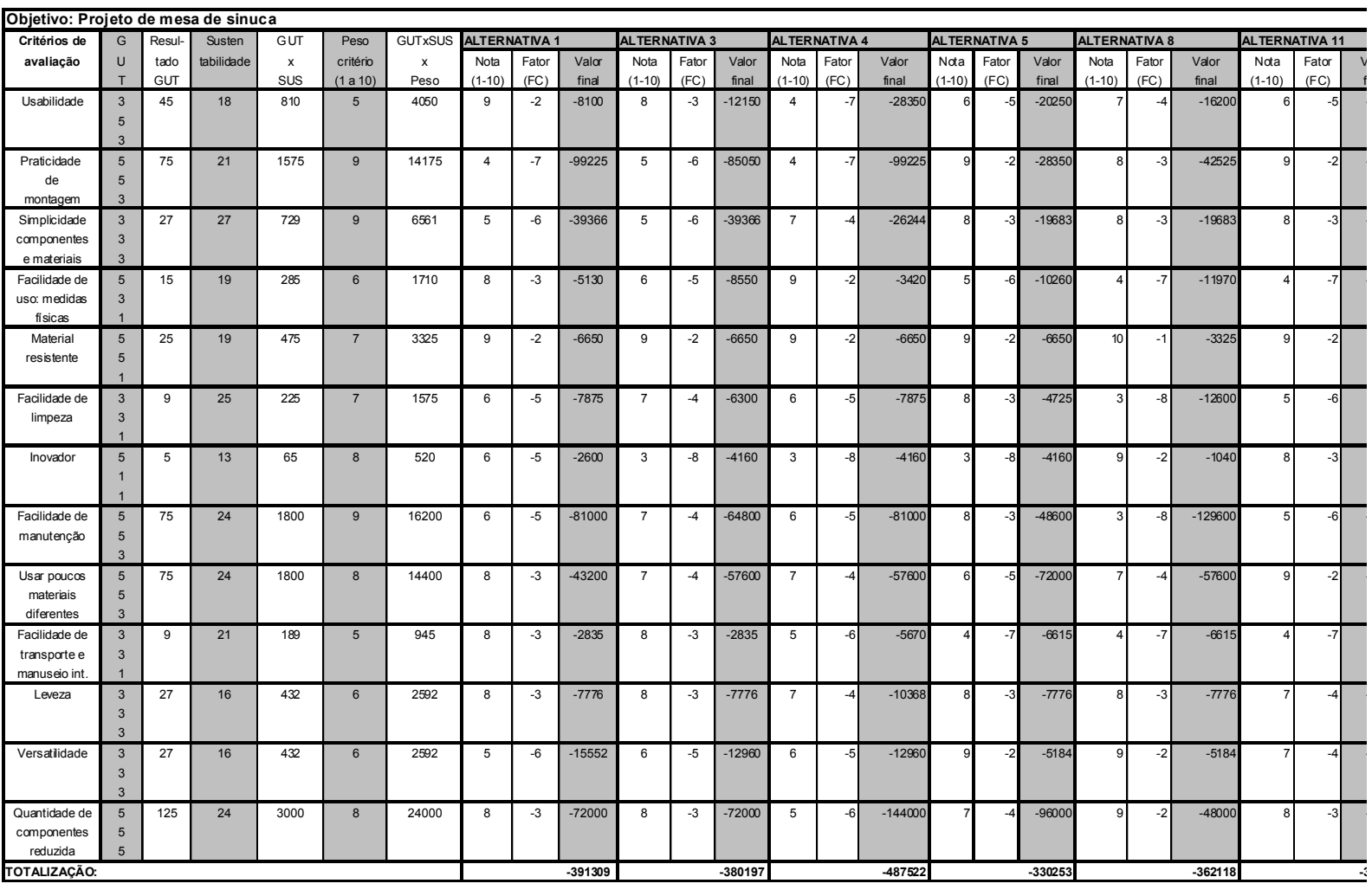

Quadro 18 - Análise dos itens desejos.

\begin{tabular}{|c|c|c|c|c|c|c|c|c|c|c|c|c|c|c|c|c|c|c|c|c|c|}
\hline \multicolumn{22}{|l|}{ Obje } \\
\hline \multirow{2}{*}{$\begin{array}{c}\text { Critérios de } \\
\text { avaliação }\end{array}$} & \multirow{2}{*}{$\begin{array}{c}\text { Peso } \\
\text { critério } \\
\text { (1 a 10) } \\
\end{array}$} & \multirow{2}{*}{$\begin{array}{l}\text { Susten } \\
\text { tabilidade }\end{array}$} & \multirow{2}{*}{$\begin{array}{c}\text { Peso } \\
x \\
\text { Sust. }\end{array}$} & \multicolumn{3}{|c|}{ ALTERNATIVA 1} & \multicolumn{3}{|c|}{ ALTERNATIVA 3} & \multicolumn{3}{|c|}{ ALTERNATIVA4 4} & \multicolumn{3}{|c|}{ ALTERNATIVA5 } & \multicolumn{3}{|c|}{ ALTERNATIVA 8} & \multicolumn{3}{|c|}{ ALTERNATIVA 11} \\
\hline & & & & $\begin{array}{l}\text { Nota } \\
(1-10)\end{array}$ & $\begin{array}{l}\text { Fator } \\
\text { (FC) }\end{array}$ & $\begin{array}{l}\text { Valor } \\
\text { final }\end{array}$ & $\begin{array}{c}\text { Nota } \\
(1-10)\end{array}$ & $\begin{array}{l}\text { Fator } \\
(\mathrm{FC})\end{array}$ & $\begin{array}{l}\text { Valor } \\
\text { final }\end{array}$ & $\begin{array}{l}\text { Nota } \\
(1-10)\end{array}$ & $\begin{array}{l}\text { Fator } \\
(\mathrm{FC})\end{array}$ & $\begin{array}{l}\text { Valor } \\
\text { final }\end{array}$ & $\begin{array}{l}\text { Nota } \\
(1-10)\end{array}$ & $\begin{array}{l}\text { Fator } \\
\text { (FC) }\end{array}$ & $\begin{array}{l}\text { Valor } \\
\text { final }\end{array}$ & $\begin{array}{l}\text { Nota } \\
(1-10)\end{array}$ & $\begin{array}{l}\text { Fator } \\
\text { (FC) }\end{array}$ & $\begin{array}{l}\text { Valor } \\
\text { final }\end{array}$ & $\begin{array}{l}\text { Nota } \\
(1-10)\end{array}$ & $\begin{array}{l}\text { Fator } \\
\text { (FC) }\end{array}$ & $v_{\varepsilon}$ \\
\hline $\begin{array}{l}\text { Quantidade de } \\
\text { acessórios }\end{array}$ & 9 & 22 & 198 & 4 & 100 & 79200 & 4 & 100 & 79200 & 8 & 100 & 158400 & 7 & 100 & 138600 & 2 & 100 & 39600 & 4 & 100 & 79. \\
\hline $\begin{array}{l}\text { Usar como } \\
\text { mesa normal }\end{array}$ & 8 & 21 & 168 & 9 & 100 & 151200 & 9 & 100 & 151200 & 9 & 100 & 151200 & 7 & 100 & 117600 & 9 & 100 & 151200 & 9 & 100 & 15 \\
\hline Atraente & 7 & 15 & 105 & 3 & 100 & 31500 & 4 & 100 & 42000 & 3 & 100 & 31500 & 9 & 100 & 94500 & 6 & 100 & 63000 & 7 & 100 & 73 \\
\hline $\begin{array}{l}\text { Disp. manter } \\
\text { a mesa plana }\end{array}$ & 8 & 14 & 112 & 1 & 100 & 11200 & 4 & 100 & 44800 & 2 & 100 & 22400 & 6 & 100 & 67200 & 6 & 100 & 67200 & 8 & 100 & 89 \\
\hline $\begin{array}{c}\text { Materiais } \\
\text { ecol. corretos }\end{array}$ & 6 & 30 & 180 & 6 & 100 & 108000 & 6 & 100 & 108000 & 9 & 100 & 162000 & 9 & 100 & 162000 & 7 & 100 & 126000 & 9 & 100 & $\overline{162}$ \\
\hline $\begin{array}{c}\text { Evitar riscos } \\
\text { no chăo }\end{array}$ & 5 & 18 & 90 & 8 & 100 & 72000 & 8 & 100 & 72000 & 9 & 100 & 81000 & 5 & 100 & 45000 & 8 & 100 & 72000 & 6 & 100 & 54 \\
\hline $\begin{array}{l}\text { Disponibilidade } \\
\text { vários modelos }\end{array}$ & 2 & 22 & 44 & 1 & 100 & 4400 & 1 & 100 & 4400 & 2 & 100 & 8800 & 1 & 100 & 4400 & 4 & 100 & 17600 & 3 & 100 & 13 \\
\hline $\begin{array}{c}\text { Disponibilidade } \\
\text { várias cores }\end{array}$ & 2 & 22 & 44 & 3 & 100 & 13200 & 3 & 100 & 13200 & 3 & 100 & 13200 & 5 & 100 & 22000 & 9 & 100 & 39600 & 5 & 100 & 22 \\
\hline TOTALZZAÇÃO: & & & & & & 470700 & & & 514800 & & & 628500 & & & 651300 & & & 576200 & & & \\
\hline
\end{tabular}

Com o término do preenchimento do quadro 18, a análise final é a subtração dos valores encontrados no referido quadro com os encontrados no quadro 17 , cálculo mostrado no quadro 19. 
Quadro 19 - FEAP-SUS: análise final

\begin{tabular}{|r|r|r|r|}
\hline Alternativa analisada & $\begin{array}{c}\text { Resultado quadro } \\
\text { desejos }\end{array}$ & $\begin{array}{c}\text { Resultado quadro } \\
\text { deveres de grau 2 }\end{array}$ & Resultado final \\
\hline 1 & 470700 & -391309 & 79391 \\
\hline 3 & 514800 & -380197 & 134603 \\
\hline 4 & 628500 & -487522 & 140978 \\
\hline 5 & 651300 & -330253 & 321047 \\
\hline 8 & 576200 & -362118 & 214082 \\
\hline 11 & 644700 & -323264 & 321436 \\
\hline 12 & 614600 & -283218 & 331382 \\
\hline
\end{tabular}

Segundo o resultado final apresentado no quadro 19, observa-se que a alternativa de número 12 foi escolhida como a mais adequada. Essa foi também a alternativa escolhida pelo autor do projeto, demonstrando uma coerência positiva da ferramenta. A alternativa de número 11 também ficou bem classificada, podendo ser uma opção para futura análise. A figura 2 ilustra a alternativa final escolhida.

Figura 2 - Alternativa escolhida

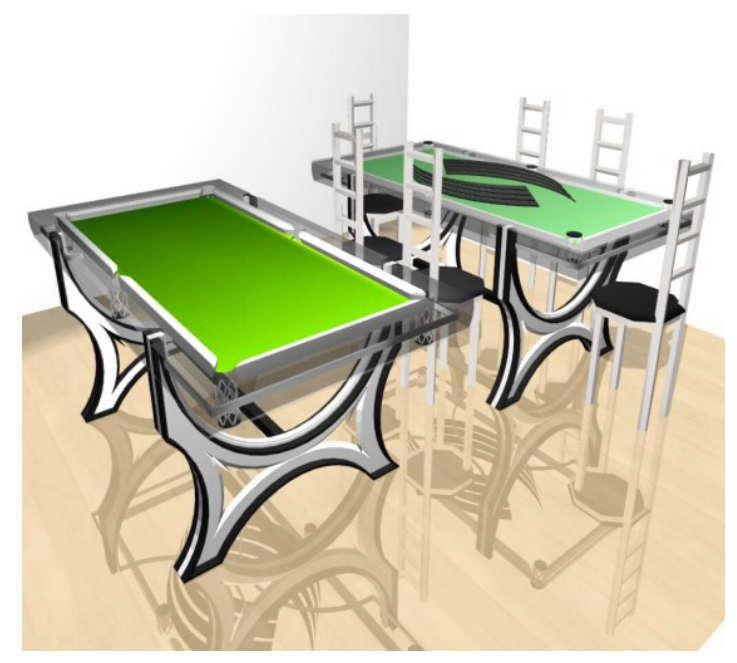

Fonte: Rigailo (2007)

O próximo capítulo apresenta uma análise final da ferramenta FEAP-SUS e recomendações para futuras pesquisas relacionadas ao tema.

\section{CONSIDERAÇÕES FINAIS}

Do mesmo modo que a análise efetuada com qualquer ferramenta ou método projetual existente, a ferramenta apresentada nessa pesquisa objetiva a redução 
dos riscos do processo de projeto, contribuindo para a redução dos recursos empregados (tempo, financeiros, etc.).

Analisando-se os resultados obtidos, pode-se concluir que a aplicação da FEAP-SUS tem como objetivo principal a melhoria da qualidade do processo projetual devendo-se levar em consideração as seguintes limitações quando de sua aplicação:

- Estabelecimento confiável das necessidades dos clientes. O marco inicial é uma bem efetuada coleta de dados junto ao público-alvo (NCs Necessidades do Clientes). Nesse ponto há um co-relacionamento da FEAP-SUS com o QFD. Para a aplicação da ferramenta não há obrigatoriedade de construção da casa da qualidade (QFD), embora esta possa ser de bastante utilidade. As necessidades dos clientes devem ser, preferencialmente, coletadas junto aos vários grupos de consumidores do produto (internos, externos e intermediários), promovendo desse modo uma boa diversidade de opiniões.

- Entendimento e correta classificação das NCs em deveres de grau 1, deveres de grau 2 e desejos (seguindo-se para isso o modelo Kano). Considerando a relação com a qualidade esperada, e considerando o modo diferencial com que cada tipo de qualidade (obrigatória, de desempenho e atrativa) é tratada, torna-se fundamental a condução bem planejada dessa etapa. Embora a responsabilidade de classificação seja do designer, projetista ou equipe de projeto, é fundamental coletar-se informações complementares e opiniões com outros profissionais indiretamente envolvidos no projeto para uma quantificação o mais próxima possível da real. A abordagem multidisciplinar nesta etapa também auxilia a equipe de projeto a rever conceitos anteriormente aceitos.

- Pesquisa junto ao mercado para correta aplicação da ferramenta GUT. Novamente o caráter multidisciplinar favorece uma quantificação mais correta.

- Determinação dos aspectos de sustentabilidade nas dimensões econômica, social e ambiental. Essa etapa, especialmente pelo conceito novo de sustentabilidade, pode apresentar um grande índice de Revista Produção Online. Florianópolis, SC, v.11, n. 2, p. 447-475, abr./jun., 2011. 
divergências de opiniões entre os membros da equipe de projeto, o que torna fundamental a troca de informações entre as várias áreas do conhecimento.

- Atribuição das notas de cada alternativa e pesos dos critérios por uma equipe multidisciplinar (evitando a priorização excessiva de determinadas abordagens - design abaixo da linha e design acima da linha). Por design abaixo da linha entende-se projetos voltados mais para a parte técnica, atributos não percebíveis pelo consumidor, mas de relevância fundamental para seu bom desenvolvimento, tendo como exemplo, componentes internos de um equipamento; e design acima da linha são as partes que conquistam o cliente, como aspectos externos de cores, estilo, textura, entre outros.

Com relação a aplicação do método, cabe as seguintes observações:

1. Provou-se ser possível o desenvolvimento de uma ferramenta de projeto para auxiliar na escolha da melhor alternativa projetual realizada após a etapa de geração de alternativas, independente do método de design utilizado.

2. De acordo com os estudos preliminares, realizado através de entrevistas e pré-testes, decidiu-se utilizar na ferramenta desenvolvida uma abordagem da sustentabilidade dividindo-se os termos em ambiental, econômica e social. Esse tipo de abordagem promoveu um melhor entendimento de cada item, facilitando a análise e, conseqüentemente, atribuição de valores numéricos.

3. A ferramenta desenvolvida permite, segundo os testes realizados, a escolha da melhor alternativa gerada, pois engloba em sua análise um conjunto amplo de critérios analisados, abordando todos os quesitos considerados importantes para o produto. Na medida em que os quesitos considerados indispensáveis promovem a eliminação da alternativa (no caso desta não abordá-lo), enquanto que os demais quesitos (não indispensáveis) são usados para comparação qualitativa/quantitativa, a ferramenta promove uma análise diferenciada de cada alternativa, ou Revista Produção Online. Florianópolis, SC, v.11, n. 2, p. 447-475, abr./jun., 2011. 
seja, a ferramenta não obriga ao designer ou equipe de projeto a utilizar a alternativa que ficou melhor colocada, mas demonstra ser esta a melhor opção (pelo menos conceitual). Ao optar por outra alternativa, que não a sugerida pela ferramenta, tem-se como analisar quais fatores são passíveis de melhoramentos e que possíveis implicações e/ou desdobramentos a escolha trará.

A validação da ferramenta foi satisfatória, pois cumpriu com os objetivos pretendidos, chegando-se a um resultado final coerente. Na aplicação do digestor de vísceras, nota-se uma alteração na alternativa escolhida sem a aplicação da variável sustentabilidade, o que demonstra a importância de sua inclusão. Já na análise da mesa de sinuca, a alternativa apontada pela ferramenta como a melhor foi a mesma escolhida pelo autor do projeto, sem que houvesse, por parte deste (pelo menos aparentemente, segundo as informações coletadas nos memoriais de projeto) maiores preocupações com respeito as questões ecológicas. Apesar de, neste caso, chegar-se ao mesmo resultado, observa-se como vantagem da aplicação da ferramenta um melhor detalhamento das necessidades dos clientes, ofertando dados para análises criteriosas para futuros re-designs.

Em função da ferramenta ter sido testada e validada utilizando-se apenas dois projetos, sugere-se as seguintes pesquisas futuras para melhor entendimento e aplicabilidade da FEAP-SUS:

- Testar a ferramenta em um projeto novo, desde o início, não apenas em projetos já finalizados. Isso dará uma melhor oportunidade de buscar informações mais detalhadas junto ao público-alvo, seja pela formatação e aplicação do briefing, como também pelas pesquisas bibliográficas e de campo a serem realizadas.

- Desenvolver um software específico, para facilitar a aplicação da ferramenta que permita uma aplicação rápida, facilitando a análise pela construção de gráficos comparativos.

- Realizar testes da FEAP-SUS em produtos projetados por empresas detentoras da certificação ISO 14.000. 


\section{REFERÊNCIAS}

ALMEIDA, Fernando. Os desafios da sustentabilidade: uma ruptura urgente. Rio de Janeiro: Elsevier, 2007.

BACK, Nelson; OGLIARI, André; DIAS, Acires; SILVA, Jonnhy Carlos da. Projeto integrado de produtos: planejamento, concepção e modelagem. Barueri, SP: Manole, 2008.

BAXTER, Mike. Projeto de produto. 2. ed. São Paulo: Edgard Blücher Ltda, 1998.

FERROLI, Paulo Cesar Machado; LIBRELOTTO, Lisiane Ilha. Método paramétrico aplicado em design de produtos. Revista Produção Online, v. 7, n. 3, nov. 2007.

LIBRELOTTO, Lisiane Ilha. Modelo para avaliação da sustentabilidade na construção civil nas dimensões econômica, social e ambiental (esa). São Paulo: Blucher Acadêmico, 2009.

MANZINI, Ezio e VEZZOLI, Carlo. O Desenvolvimento de produtos sustentáveis os requisitos ambientais dos produtos industriais. São Paulo: EdUSP, 2008.

MENEZES, Luís César de Moura. Gestão de projetos. São Paulo: Atlas, 2001.

PAULI, Gunter. Emissão zero: a busca de novos paradigmas. Porto Alegre: EDIPUCRS, 1996.

RIGAILO, Geldson Danilo. Mesa de sinuca. Balneário Camboriú: UNIVALI/Design Industrial, 2008.

ROZENFELD, Henrique et al. Gestão de desenvolvimento de produtos: uma referência para a melhoria do processo. São Paulo: Saraiva, 2006.

SANTOS, Flavio Anthero Nunes Vianna dos. MD3E (método de desdobramento em 3 etapas): proposta de método aberto de projeto para ensino de Design Industrial. Doutorado / Gestão Integrada do Design - Programa de Engenharia de Producao, EPS/UFSC, Florianópolis, 2005.

SILVA, Eduardo Sanches. Visão sistêmica do gerenciamento de processos. Apostila da disciplina de Planejamento do Produto, PPGEP-UFSC, 2004.

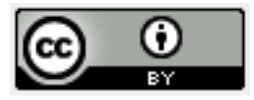

Artigo recebido em 20/04/2010 e aceito para publicação em 10/04/2011. 